\title{
Vaccination Against COVID-19, A Healthy Alternative
}

\author{
Juan Carlos Mirabal Requena ${ }^{1 *}$ and Belkis Alvarez Escobar ${ }^{2}$ \\ ${ }^{1}$ Master in Natural Medicine and Bioenergetics, First and Second-Degree Specialist in Comprehensive General Medicine, First \\ Degree Specialist in Physical Medicine and Rehabilitation, Assistant Principal Professor, Assistant Researcher, Sancti Spíritus \\ University of Medical Sciences, Rector, Sancti Spíritus, Cuba
}

${ }^{2}$ Master in Satisfactory Longevity, First and Second-Degree Specialist in Comprehensive General Medicine, Assistant Principal Professor, Added Researcher, Sancti Spíritus University of Medical Sciences, Methodological Department, Sancti Spíritus, Cuba

*Corresponding author: Juan Carlos Mirabal Requena, Master in Natural Medicine and Bioenergetics, First and Second-Degree Specialist in Comprehensive General Medicine, First Degree Specialist in Physical Medicine and Rehabilitation, Assistant Principal Professor, Assistant Researcher, Sancti Spíritus University of Medical Sciences, Rector, Sancti Spíritus, Cuba

\begin{tabular}{|c|c|}
\hline ARTICLE INFO & ABSTRACT \\
\hline Received: 㓞 October 08, 2021 & Citation: Juan Carlos Mirabal Requena, Belkis Alvarez Escobar. Vaccination Against \\
\hline Published: 幽 October 20, 2021 & $\begin{array}{l}\text { COVID-19, A Healthy Alternative. Biomed J Sci \& Tech Res 39(3)-2021. BJSTR. } \\
\text { MS.ID.006311. }\end{array}$ \\
\hline
\end{tabular}

\section{Commentary}

Since the first reported cases of COVID-19, the world has been grappling with this disease and its consequences. Confirmed cases are increasing, the numbers of daily deaths are chilling, countries suffer the paralysis of social life and the national economy. Meanwhile, the scientific community has been racing against time to find effective vaccines in response to the pandemic. Vaccines have the function of preparing the immune system to detect and fight specific viruses and bacteria, achieving that if the body is exposed to pathogenic germs, it will be ready to destroy them immediately and thus prevent disease. It is sought with the vaccine, protection against the most severe forms of the disease and mortality. In June 2021, the World Health Organization (WHO) reported the existence of 185 vaccine candidates in the preclinical development stage and another 102 in the clinical trial phase [1]. Currently, the WHO has authorized the use of six vaccines, others are still being studied for subsequent approval. National Regulatory Agencies have authorized COVID-19 vaccines in specific countries [2].

The first mass vaccination program started in early December 2020. The great spread of the novel coronavirus increases the demand for vaccines, but their limited production will lead to the use of all formulations that prove to be suitable. The effectiveness of a vaccine is measured by the percentage reduction in the frequency of infections among vaccinated people compared to the frequency among those who were not vaccinated, assuming that the vaccine is the cause of this reduction. Effectiveness represents the health benefits provided by a vaccination program in the population when the vaccines are administered in the real or usual conditions of daily care practice or program development [3]. Although all currently approved vaccine platforms have been shown to stimulate both the humoral and cellular responses, there is a great unresolved question: How long does the immunity conferred by vaccines last? Nevertheless, the vaccination option is a healthy choice for the general population.

Vaccination has been intensifying in risk groups such as those over 60 years of age, patients with comorbidities such as heart disease, diabetes, among others. Pregnant women have been prioritized to achieve an ideal immunization, as this group is one of the most disadvantaged before the disease, due to the physiological changes of pregnancy and the decrease in the immune system of the pregnant woman. According to data provided by the Pan American Health Organization (PAHO), more than 270,000 pregnant women have fallen ill with COVID-19 in the Americas and more than 2,600 have died from that cause since the start of the pandemic, it is also important to take into account breastfeeding women [4]. The pediatric population is another of the risk populations towards which vaccine interventions are currently directed. Being especially 
vulnerable to COVID-19, health personnel have been among the first to receive any of the existing vaccines. This occupational group is at higher risk for severe COVID-19.

Until today, vaccination is the best strategy to control the spread of the virus, but it should not be forgotten that changes in personal behavior and attitude will be increasingly necessary. The biosafety and self-care measures that the population must maintain must be a priority to be able to return to a social normality that is so longed for. Getting the largest number of people vaccinated as quickly and globally as possible, along with non-pharmacological interventions, could ensure that the virus can be suppressed rather than spread [5]. The news reflects new outbreaks and the increase in cases in many countries, even as vaccination campaigns are progressing The population is concerned about the increase in cases, which occurs at the same time as the introduction of vaccines. This largely depends on the type of variant that circulates in the region, the Delta is much more virulent and therefore the contagion increases in its presence, despite the fact that there is a certain level of population vaccination.

Vaccination leads to collective protection, although there will be patients in the group, they will not be able to transmit the disease, either due to the immunization conferred by the vaccine or because they were convalescent, this is the so-called herd immunity. The aim of the vaccine is to reduce deaths, serious and critical cases, intensive care units, hospitalizations and then the incidence rate [6]. Cuba began the intensive vaccination program on May 12, 2021, and as of September of the same year, more than 14 million doses of nationally produced vaccines had been applied. In a staggered manner, the strategy for the development, introduction and extension of Cuban vaccines has been applied, which ranges

ISSN: 2574-1241

DOI: 10.26717/BJSTR.2021.39.006311

Juan Carlos Mirabal Requena. Biomed J Sci \& Tech Res

CC $($ This work is licensed under Creative Commons Attribution 4.0 License

Submission Link: https://biomedres.us/submit-manuscript.php from clinical trials, studies in risk groups, health intervention to mass vaccination, a stage in which the country is immersed. Cuba already has three quality, safe and effective immunogens. Abdala approved in July 2021 and Soberana 02 together with Soberana Plus authorized in August of the same year [7].

One of the worst health situations in the history of mankind is being experienced. The loss of human life is quantified in the thousands, in addition to the situations of social deprivation and health that are worsening in the world population. Faced with this situation, it is necessary to consider the research progress, the production of science based on evidence, to respond in the best way to this pandemic caused by COVID-19. Vaccination, without a doubt, is an alternative that raises the hope of success in the face of this disease.

\section{References}

1. Armas Pedraza L (2021) Cuban vaccine candidates: some results and news. Cubahora.

2. (2021) Pan American Health Organization. Frequently Asked Questions: COVID-19 Vaccines. OPS.

3. Santucci N, Villar SR (2021) Immunological assessment of COVID-19 vaccines. IntraMed.

4. Loewy MA (2021) Pan American Health Organization urges to vaccinate all pregnant women against COVID-19 from the first trimester. Medscape.

5. Rella SA, Kulikova YA, Dermitzakis ET, Kondrashov F (2021) Rates of SARS-CoV-2 transmission and vaccination impact the fate of vaccineresistant strains. SciRep 11(1): 15729.

6. (2021) Cubadebate. Impact of the vaccination process in Cuba and its effectiveness. Cubadebate.

7. (2020) Redacción MINSAP. Ministry of Health: "The emergency use authorization granted by CECMED, to the Soberana 02 and Soberana Plus vaccines, is pride and commitment for everyone.

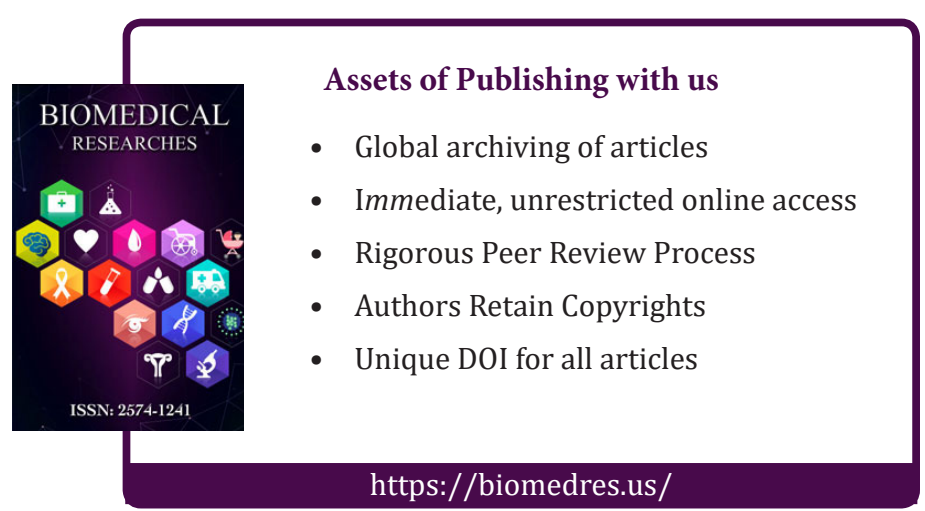

